\section{AB0256 \\ CLINICO- BIOLOGICAL PROFILE OF RHEUMATOID ARTHRITIS WITH PERIODONTITIS AND PORPHYROMONAS GINGIVALIS}

Farida Mechid ${ }^{1}$, Houda Hafirassou ${ }^{1}$, Malika Meddad ${ }^{2}$, Samir Salah ${ }^{3}$ Saida Merad ${ }^{4}$, Nawel Blidi ${ }^{1}$, Chafia Makhloufi-Dahou ${ }^{1} .{ }^{1}$ Rheumatology, Mohamed Lamine Debaghine hospital, ALGIERS, Algeria; ${ }^{2}$ Periodontology, Mustapha Bacha Hospital, ALGIERS, Algeria; ${ }^{3}$ Immunology. Dely brahim, institut Pasteur, ALGIERS, Algeria; ${ }^{4}$ Bacteriology. Dely brahim, institut Pasteur, Algiers, Algeria, ALGIERS, Algeria

Background: The Periodontitis (PD) is currently recognized as a risk factor of occurrence of the rheumatoid arthritis(RA). The porphyromonas gingivalis (P.gingivalis) figure among the main germs incriminated in the occurrence of the PD. Previous studies have shown that antibodies to $P$. gingivalis are associated with anti-CCP antibody in patients with RA However others studies have not demonstrated this association.

Objectives: The aim of this study was to seek for a possible association between clinico-biological parameters of the RA and the presence of the P.gingivalis.

Methods: We conducted a prospective study of 69 patients with early rheumatoid arthritis ( $\leq 2$ years), naive of biotherapy. Smokers, diabetics, and subjects who received dental care and those who used antibiotics in the previous 6 months were not included. Periodontal status, demographic, clinical activity, and anticyclic citrullinated peptide antibodies (antiCCP) parameters were determined. The $\mathrm{P}$. gingivalis has been searched in patients with a PD. We sought to investigate an association between Rheumatoid disease activity (DAS28), anticyclic citrullinated peptide antibodies (anti-CCP) and P.gingivalis.

Results: The mean age of our patients was $40.75 \pm 12.04$, the mean duration of the illness was $14.30 \pm 6.76$ months (extremes: 1-24 months). ACPA was detected in $88 \%$ of patients and the mean titre was 255.57 \pm 409.78 . $43 \%$ of patients have presented a PD. The P.gingivalis has been detected in $59 \%$ of PD. The means DAS28 of patient with and without P.gingivalis is respectively $4.40 \pm 1.32$ and $4.15 \pm 1.45$, and there was no significant difference $(p=0.65)$. There was also no association observed between anti CCP and the presence of P.gingivalis(the mean titre of anti CCP was $249.47 \pm 294.58$ with P.gingivalis and $258.67 \pm 93.48$ without P.gingivalis, $\mathrm{p}=0.74$ )

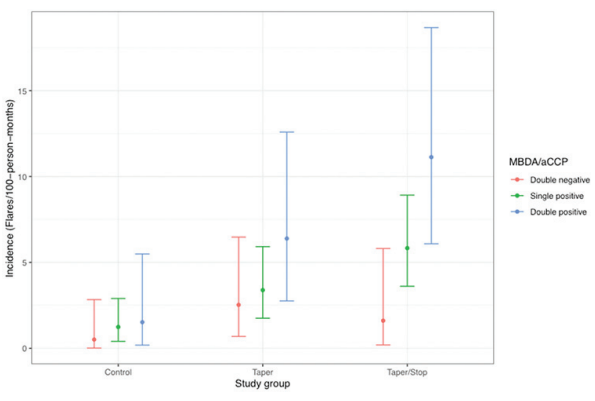

Conclusion: This study showed that periodontitis is frequent in rheumatoid arthritis. More than half of our patients suffering of periodontitis were infected by porphyromonas gingivalis. Rheumatoid disease activity does not seem to be related to porphyromonas gingivalis. In addition there was no association between anti-CCP antibody and the presence of porphyromonas gingivalis.

\section{REFERENCES}

[1] Johansson L, Sherina N, Kharlamova N, Potempa B, Larsson B, Israelsson L, Potempa J, Rantapää-Dahlqvist S, Lundberg K. Concentration of antibodies against Porphyromonas gingivalis is increased before the onset of symptoms of rheumatoid arthritis. Arthritis Research \& Therapy 2016;18: 201.

[2] Bello-Gualtero JM, Lafaurie GI, Hoyos LX, et al. Periodontal Disease in Individuals With a Genetic Risk of Developing Arthritis and EarlyRheumatoid Arthritis: A Cross-Sectional Study. J Periodontol. 2016;87(4):346-56.

[3] Fisher BA, Cartwright AJ, Quirke AM, de Pablo P, Romaguera D, Panico $\mathrm{S}$, et al. Smoking, Porphyromonas gingivalis and the immune response to citrullinated autoantigens before the clinical onset of rheumatoid arthritis in a Southern European nested case-control study. BMC Musculoskelet Disord. 2015;16:331.

[4] Cheng Z, Meade J, Mankia K, Emery P, Devine DA. Periodontal disease and periodontal bacteria as triggers for rheumatoid arthritis. Best Pract Res Clin Rheumatol. 2017;31(1):19-30.

Disclosure of Interests: None declared

DOI: 10.1136/annrheumdis-2019-eular.3342

\section{$\mathrm{AB} 0257$ \\ FATIGUE LEVELS PREDICT OTHER PATIENT REPORTED OUTCOMES AND DISEASE ACTIVITY SCORES: RESULTS FROM A LONGITUDINAL STUDY OF RA PATIENTS INITIATING BDMARD THERAPY}

Hilde Berner Hammer ${ }^{1}$, Brigitte Michelsen ${ }^{2}$, Sella Aarrestad Provan ${ }^{1}$, Till Uhlig ${ }^{1}$ Tore K. Kvien'. ' Diakonhjemmet Hospital, Dept. of Rheumatology, Oslo, Norway, ${ }^{2}$ Hospital of Southern Norway Trust, Division of Rheumatology, Department of Medicine, Kristiansand, Norway

Background: Fatigue is a sensation of weakness and lack of energy which is common in patients with rheumatoid arthritis (RA), contributing to reduced quality of life. However, there are few studies on the longitudinal influence of fatigue on patient reported outcome measures (PROMs).

Objectives: The present study explores the impact of fatigue on PROMs, clinical, laboratory and ultrasound (US) assessments.

Methods: A total of 208 patients with established RA (mean (SD) age 53 (13) years, disease duration 10 (9) years, $81 \%$ women, $79 \%$ anti-CCP positive) were examined when initiating bDMARDs and assessed at baseline and after $1,2,3,6$ and 12 months, including fatigue $(0-10$, as part of the RAID score), PROMs (joint pain VAS, patient's global disease activity VAS (PGA), MHAQ, pain catastrophizing (PC), SF-36 Mental Health scale score (SF36MH)), clinical examinations (performed by a study nurse including examiner's global disease activity VAS (EGA), 28 tender and swollen joint counts (TJC, SJC)) and laboratory variables (ESR and CRP). US examinations (semi-quantitative scoring (0-3)) of grey scale (GS) and power Doppler (PD) were performed of 36 joints and 4 tendons by one rheumatologist ( $\mathrm{HBH}$; Siemens Acuson Antares, excellence version, 5-13 $\mathrm{MHz}$ probe). The clinical disease activity scores (CDAS) DAS28, CDAl and SDAl were calculated for all visits. Correlations were assessed by Spearman's rho. The predictive value of baseline fatigue on several dependent variables (PROMs, CDAS, clinical assessments) at all visits after baseline was explored by use of multiple linear regression analysis with adjustment for demographic values (age, sex and disease duration) and baseline inflammatory activity (CRP and sum score GS).

Results: Fatigue levels diminished during follow-up (baseline median (IQR) 5 (3-7), 12 months 2 (1-5)). Table 1 shows the high cross-sectional correlations between fatigue and PROMs/CDAS scores, low correlations with $\mathrm{EGA} / \mathrm{SJC} / \mathrm{CRP}$ and lack of correlations with US assessments. Baseline fatigue predicted PROMs and CDAS scores at all examinations (table 2). No/low associations were found between baseline fatigue and SJC/EGA sum score PD at follow-up.

Conclusion: Fatigue was highly correlated with PROMS and composite scores at all timepoints. The level of baseline fatigue predicted PROMs and composite scores at follow-up, but not objective inflammatory measures. Thus, the degree of fatigue should be taken into account when composite scores are used for evaluation of inflammatory activity in established RA patients.

\begin{tabular}{|c|c|c|c|c|c|c|}
\hline \multicolumn{7}{|c|}{$\begin{array}{l}\text { Table } 1 . \\
\text { Cross-sectional correlations between fatigue and several variables (Spearman's rho) at all visits } * p<0.05, * * p<0.001\end{array}$} \\
\hline & $\begin{array}{l}\text { Baseline } \\
n=208\end{array}$ & $\begin{array}{l}1 \text { month } \\
n=208\end{array}$ & $\begin{array}{l}2 \text { months } \\
n=204\end{array}$ & $\begin{array}{l}3 \text { months } \\
n=197\end{array}$ & $\begin{array}{l}6 \text { months } \\
n=183\end{array}$ & $\begin{array}{l}12 \text { months } \\
n=152\end{array}$ \\
\hline Patient's global VAS & $0.72^{* *}$ & $0.73^{* *}$ & $0.69 * *$ & $0.70^{* *}$ & $0.74^{* *}$ & $0.67 * *$ \\
\hline Joint pain VAS & $0.64^{* *}$ & $0.69 * *$ & $0.63^{* *}$ & $0.62^{* *}$ & $0.67^{* *}$ & $0.49 * *$ \\
\hline MHAQ & $0.63^{* *}$ & $0.59 * *$ & $0.53^{* *}$ & $0.51^{* *}$ & $0.57 * *$ & $0.47^{* *}$ \\
\hline SF36 Mental Health scale score & $-0.57^{* *}$ & $-0.66^{* *}$ & $-0.54 * *$ & $-0.56^{* *}$ & $-0.55 * *$ & $-0.52 * *$ \\
\hline $\begin{array}{l}\text { Pain catastrophizing } \\
\end{array}$ & $0.58^{* *}$ & $0.61^{* *}$ & $0.53^{* *}$ & $0.49 * *$ & $0.46 * *$ & $0.45 * *$ \\
\hline DAS28 & $0.60^{* *}$ & $0.56^{* *}$ & $0.44 * *$ & $0.45^{* *}$ & $0.51^{* *}$ & $0.38^{* *}$ \\
\hline CDAI & $0.56^{* *}$ & $0.52^{* *}$ & $0.46^{* *}$ & $0.47^{* *}$ & $0.52^{* *}$ & $0.41^{* *}$ \\
\hline SDAI & $0.56^{* *}$ & $0.52^{* *}$ & $0.45^{* *}$ & $0.47^{* *}$ & $0.51^{* *}$ & $0.41^{* *}$ \\
\hline 28 tender joint count & $0.47^{* * *}$ & $0.50^{* * *}$ & $0.40^{* * *}$ & $0.46^{* * *}$ & $0.47^{* * *}$ & $0.32^{* * *}$ \\
\hline Assessor's global VAS & $0.31^{* *}$ & $0.29 * *$ & $0.26^{* * *}$ & $0.29 * *$ & $0.32^{* * *}$ & $0.21^{*}$ \\
\hline 28 swollen joint count & $0.20^{*}$ & 0.12 & 0.12 & 0.05 & 0.11 & 0.01 \\
\hline CRP & $0.14^{*}$ & 0.11 & 0.11 & 0.10 & $0.18^{*}$ & 0.08 \\
\hline Sum score GS & 0.00 & 0.01 & 0.00 & 0.01 & 0.04 & 0.04 \\
\hline Sum score PD & 0.02 & 0.02 & 0.01 & 0.01 & 0.04 & 0.04 \\
\hline
\end{tabular}

Table 2.

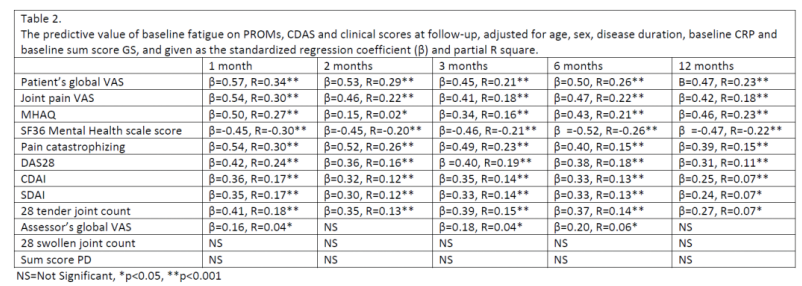

Disclosure of Interests: Hilde Berner Hammer Grant/research support from: AbbVie, Pfizer and Roche, Paid instructor for: AbbVie, Pfizer, UCB, Novartis, Roche, Speakers bureau: AbbVie, Pfizer, UCB, Novartis, Roche Brigitte Michelsen Grant/research support from: Unrestricted grant: 
Novartis, Consultant for: Novartis, UCB, Sella Aarrestad Provan Consultant for: Novartis, Speakers bureau: Lilly, Till Uhlig Consultant for: Grünenthal, Novartis, Speakers bureau: Grünenthal, Novartis, Tore K. Kvien Grant/ research support from: AbbVie, BMS, MSD, Pfizer, Roche and UCB., Consultant for: AbbVie, Biogen, BMS, Boehringer Ingelheim, Celgene, Celltrion, Eli Lilly, Hospira, Merck-Serono, MSD, Novartis, Oktal, Orion Pharma, Pfizer, Roche, Sandoz, Sanofi, Mylan and UCB, Speakers bureau: AbbVie, Biogen, BMS, Boehringer Ingelheim, Celgene, Celltrion, Eli Lilly, Hospira, Merck-Serono, MSD, Novartis, Oktal, Orion Pharma, Pfizer, Roche, Sandoz, Sanofi and UCB

DOI: 10.1136/annrheumdis-2019-eular.1538

\section{AB0258 POTENTIAL ROLE OF MEAN PLATELET VOLUME AND RED BLOOD CELL DISTRIBUTION WIDTH AS A BIOMARKER FOR CLINICAL AND SONOGRAPHIC ACTIVITY IN RHEUMATOID ARTHRITIS PATIENTS}

Waleed Hassan ${ }^{1}$, Mounir Elhanafi ${ }^{1}$, Refaat Eltanawy ${ }^{1}$, Rehab Shehab El-Din ${ }^{2}$. ${ }^{1}$ Benha University, Rheumatology and Rehabilitation, Benha, Egypt, ${ }^{2}$ Kafr elshikh general hospital, Rheumatology and Rehabilitation, Kafr elshikh, Egypt

Background: Red cell distribution width (RDW) reflects the variation in the circulating erythrocytes size (anisocytosis) that can increase in chronic inflammation due to ineffective erythropoiesis [1], while mean platelet volume (MPV) reveals the average size of platelets and may disclose its activation. Both are typically included in the complete blood count (CBC) and have been studied as a possible indicator of disease activity in many inflammatory conditions [2].

Objectives: This study aimed to assess the relationship between MPV and RDW levels and various rheumatoid arthritis (RA) clinical,laboratory and ultrasongraphic disease activity parameters in patients with recent onset RA before and after initiation of therapy.

Methods: We assessed MPV and RDW in blood samples obtained from 60 recent onset RA patients and 30 healthy controls at baseline and 4 months after initiation therapy with non-biological disease modifying antirheumatic drugs (DMARDS). Disease activity was calculated using the 28 joint counts (DAS28) and musculoskeletal ultrasound examination (MSUS) was performed at baseline and after 4 months using a 12-joint score (bilateral elbow, wrist, $2^{\text {nd }}$ metacarpophalangeal $(\mathrm{MCP})$, 3rd MCP, knee, ankle) [2]; Erythrocyte sedimentation rate (ESR), C-reactive protein (CRP) levels, rheumatoid factor (RF) titre and anti-cyclic citrullinated peptide (anti-CCP) antibodies titre were measured and the health assessment questionnaire (HAQ) score was documented.

Results: Baseline RDW was significantly increased in RA (15.16 $\pm 3.63 \%$ ) compared to its level in the healthy controls $(12.16 \pm 1.43 \%) \quad(p<0.001)$. While, there was no significant difference in MPV between RA and control groups (10.92 $\pm 2.02 \mathrm{fl}$ and $10.08 \pm 0.88 \mathrm{fl}$ respectively) $(p=0.2)$.

In RA patients, baseline RDW significantly correlated with $\operatorname{CRP}(r=0.39$, $p<0.05)$, DAS28 $(r=0.47, p<0.05)$, grey scale (GS) $(r=0.53, p<0.05)$ and power Doppler $(\mathrm{PD})(\mathrm{r}=0.56, \mathrm{p}<0.001)$ synovitis scores. Also, RDW at 4 months follow up significantly correlated with the DAS28 $(r=0.42$, $p<0.05)$, GS score $(r=0.45, p<0.05)$. MPV showed no significant correlation with clinical, laboratory and ultrasonographic parameter of RA disease activity.

Baseline RDW ( $p=0.02$ ) was shown to be comparable to ESR ( $p=0.03$ ) but less than CRP $(p=0.001)$ at predicting PD synovitis score.

Conclusion: Rheumatoid arthritis patients have significantly increased RDW levels that remarkably correlated with clinical, laboratory and MSUS parameters of inflammations suggesting that it could be a useful marker to reflect RA disease activity. RDW could be a useful biomarker to predict treatment outcome in RA patient. In this regard, MPV had poor correlations.

\section{REFERENCES}

[1] Aksoy ŞN, Savaş E, Sucu M, Kisacik B, Kul S, Zengin O. Association between red cell distribution width and disease activity in patients with Behcet's disease. J Int Med Res. 2015 Dec;43(6):765-73.

[2] Tecer D, Sezgin M, Kanık A, İncel NA, Çimen ÖB, Biçer A, Şahin G. Can mean platelet volume and red blood cell distribution width show disease activity in rheumatoid arthritis?. Biomark Med. 2016 Sep; 10(9):967-74

[3] Naredo E, Rodríguez M, Campos C, Rodríguez-Heredia JM, Medina JA, Giner E, et al. Validity, reproducibility, and responsiveness of a twelve-joint simplified power Doppler ultrasonographic assessment of joint inflammation in rheumatoid arthritis. Arthritis Rheum 2008;59(4):515-22.

Disclosure of Interests: None declared

DOI: 10.1136/annrheumdis-2019-eular.5809

\section{AB0259 \\ FOUR COMORBIDITY INDEXES AMONG PATIENTS WITH RHEUMATOID ARTHRITIS}

Yun-Ju Huang ${ }^{1}$, Chang-Fu Kuo ${ }^{1}$, Jung-Sheng Chen ${ }^{2}$, Shue-Fen Luo ${ }^{1} .{ }^{1}$ Division of Rheumatology, Allergy and Immunology, Taoyuan City, Taiwan, Republic of China; ${ }^{2}$ Center fo big data analytics and statistics, Taoyuan City, Taiwan, Republic of China

Background: Previous studies have reported an increased risk of multiple comorbidities in people with RA therefore it is necessary to systematically quantify the comorbidity burden of these patients.[1] The comorbidity index is a tool developed under this concept and has multiple clinical and research uses.

Objectives: We compared four comorbidity indexes and mortality rate in patients with rheumatoid arthritis in Taiwan (Charlson Comorbidity Index (CCl), Elixhauser Comorbidity Index (ECl), Mutimorbidity index (MMI), Rheumatic Disease Comorbidity Index (RDCl))

Methods: All patients with rheumatoid arthritis diagnosed during 1998 2008 in Taiwan were identified using the Taiwan National Health Insurance Database and followed up to 31 Dec 2013. One-year mortality rate and 5-year mortality rate were compared using $\mathrm{CCl}, \mathrm{ECl}, \mathrm{MMI}$ and $\mathrm{RDCl}$. High risk group for each index was defined as around the top $20 \%$ patients. A discrimination analysis was performed to compare the predictive ability of the model against the base model using the change of Harrell's c-statistics and the Akaike information criterion (AIC).

Results: Among 24767 patients with rheumatoid arthritis, median age at diagnosis is 51 years old and female is $79.2 \%$. The one-year and 5 -yea mortality rate (per 1000 people) is 41 vs. 177 in CCl, 43 vs. 135 in $\mathrm{ECl}, 43$ vs. 169 in $\mathrm{MMI}, 43$ vs. 159 in RDCl. (Low risk group vs. high risk group) The one-year and 5-year mortality rates all are higher in the high risk group compared with low risk group using four comorbidity indexes. The 5-year mortality rate rises up rapidly both in low risk group and high risk group using four comorbidity indexes. The discrimination analysis showed MMI predicted one-year and 5-year mortality best. (Harrell's c-statistics 0.796 in one-year mortality and 0.802 in 5-year mortality) $\mathrm{ECl}, \mathrm{MMI}$ and $\mathrm{RDCl}$ are all good at predicting mortality as well.

Conclusion: Our study showed mortality rate increased in patients after rheumatoid arthritis was diagnosed. All four comorbidity index score during diagnostic period predicted one-year and 5-year mortality rate well both in high risk and low risk group. Clinicians should screen different comorbidities, determine primary prevention and control disease activity to improve the functional status, quality of life and mortality of rheumatoid arthritis, especially in the patients with initial high comorbidity index scores.

\section{REFERENCE}

[1] Baillet, A., et al., Points to consider for reporting, screening for and preventing selected comorbidities in chronic inflammatory rheumatic diseases in daily practice: a EULAR initiative. Ann Rheum Dis, 2016. 75(6): p. 965 73.

Table 1. 1-year and 5-year mortality analysis for four comorbidity indexes.

\begin{tabular}{lcc}
\hline & \multicolumn{2}{c}{ Mortality rate (per 1000 people) } \\
\hline Comorbidity indexes & 1 -year & 5 -year \\
\hline CCI & 3 & 41 \\
Low risk $(0-1)$ & 23 & 177 \\
High Risk $(>1)$ & & \\
ECI & 4 & 43 \\
Low risk $(0-3)$ & 15 & 135 \\
High Risk $(>3)$ & & \\
MMI & 4 & 43 \\
Low risk $(0-1)$ & 19 & 169 \\
High Risk $(>1)$ & & \\
RDCl & 4 & 43 \\
Low risk $(0-2)$ & 18 & 159 \\
High Risk $(>2)$ &
\end{tabular}

High risk group for each index was defined as around the top $20 \%$ patients.

Table 2. The four comorbidity indexes discrimination for 1 - and 5-year survival in patients with RA.

\begin{tabular}{lcccc}
\hline Models & \multicolumn{2}{c}{ 1-year mortality } & \multicolumn{2}{c}{ 5-year mortality } \\
\cline { 2 - 5 } & $\begin{array}{l}\text { Harrell's c- } \\
\text { statistics }\end{array}$ & AIC & $\begin{array}{c}\text { Harrell's c- } \\
\text { statistics }\end{array}$ & AIC \\
\hline Base model & 0.744 & 1868 & 0.777 & 10281 \\
Base model+ CCl & 0.796 & 1783 & 0.802 & 9879 \\
Base model+ ECl & 0.772 & 1829 & 0.793 & 10024 \\
Base model+ MMI & 0.779 & 1821 & 0.792 & 10038 \\
Base model+ & 0.773 & 1817 & 0.791 & 10048 \\
RDCl & & & & \\
\hline
\end{tabular}

